\title{
Low-volume ulnar
}

nerve block within the axillary sheath for the treatment of reflex

\begin{abstract}
A case is described of reflex sympathetic dystrophy (RSD) of the upper limb following cerebral arteriography via the subclavian artery. The pain started in the hand and forearm but, over several weeks, spread to involve the whole arm. After identifying the ulnar nerve in the axillary bundle with a stimulator, a series of small volume injections (bupivacaine $0.5 \%$ with epinephrine $2.5 \mathrm{ml}$ and methyl-prednisolone $40 \mathrm{mg}$ ) was given. These relieved the pain and reversed the trophic changes of RSD. It is suggested that this approach is a useful alternative treatment in cases of RSD of the upper extremity.
\end{abstract}

Un cas de dystrophie sympathique réflexe (DSR) du membre supérieur est décrit après artériographie cérébrale via l'artère sousclavière. La douleur a débuté dans la main et l'avant-bras mais après plusieurs semaines, elle s'est étendue pour atteindre tout le bras. Après identification du nerf cubital dans le plexus axillaire avec un stimulateur, une série d'injections à petit volume (bupivacaïne $0,5 \%$ avec épinéphrine $2,5 \mathrm{ml}$ et méthylprednisolone $40 \mathrm{mg}$ ) furent administrées. Ceci a soulagé la douleur et renversé les changements trophiques du RSD. Il est suggéré que cette approche soit une alternative thérapeutique utile dans les cas de DSR du membre supérieur.

\section{Key words}

ANAESTHETIC TECHNIQUES: regional, axillary;

COMPLICATIONS: angiography;

PAIN: reflex sympathetic dystrophy.

From the Shenandoah Valley Pain Clinic, Staunton, Virginia 24401 and Department of Anesthesiology, Ohio State University, Columbus, Ohio.

Address correspondence to: Dr. David S. Klein, PO Box 509, Staunton, Virginia 24401.

Accepted for publication 19th March, 1991.
Reflex sympathetic dystrophy (RSD) resulting from surgery and other medical interventions is unusual but may be incapacitating. Damage to the brachial plexus can result from iatrogenic laceration, but the subsequent development of reflex sympathetic dystrophy is rare. Of the many approaches to therapy, none has proved to be uniformly effective. A novel approach to the treatment of RSD is presented.

\section{Case report}

A 57-yr-old, right-handed white woman with dietcontrolled diabetes mellitus and hypertension presented for evaluation of bilateral carotid stenosis and transient ischaemic attacks nine months after resection of an abdominal aortic aneurysm. Cerebral arteriography was performed using the Seldinger technique via the right axillary artery. A \#6.5 Fr catheter was inserted and advanced to the aortic arch. During the initial arterial cannulation, which was performed before arterial dilation, the patient complained of sudden, severe pain, weakness, and anaesthesia in the distribution of the ulnar nerve. Angiography proceeded uneventfully, and the patient was informed of the likelihood of damage to the ulnar nerve within the axillary sheath.

Over a period of several weeks after the angiography, the patient noticed the gradual onset of increasingly severe, constant, and unrelenting burning pain along the medial portion of the right hand and forearm up to the elbow. The severity of the pain gradually increased and it spread to the entire hand and arm. The pain was not considered to warrant a delay of surgery, and bilateral carotid endarterectomies were performed in two stages. The patient recovered from both operations uneventfully.

Over the ensuing months, the patient gradually developed profound weakness of the right hand. Diffuse muscular atrophy developed in the upper extremity, and increasing numbness developed over the hand and forearm. Hypaesthesia and vasoconstriction became more pronounced, and the pain became incapacitating. The patient received oral prednisone, $20 \mathrm{mg}$ per day, for what 
was diagnosed as posttraumatic neuritis. After one month, the pain decreased, but returned after attempts to switch the therapeutic regimen to an alternating day schedule. The patient became Cushingoid, increasingly weak, and developed a steroid myopathy that resulted in wheelchair dependence.

She was referred to the pain clinic, where the diagnosis of reflex sympathetic dystrophy was made. Stellate ganglion block was considered to be difficult due to the scars resulting from the carotid endarterectomy. As an alternative, axillary block was performed at the original arterial cannulation site. Using a Dupaco model 54120 peripheral nerve stimulator, the ulnar branch was located with a 25 -gauge needle. Bupivacaine, $0.5 \%$ with epinephrine $1: 200,0002.5 \mathrm{ml}$ and methylprednisolone 40 $\mathrm{mg}, 0.5 \mathrm{~m}$ was injected. Complete pain relief, anaesthesia over the ulnar distribution with sparing of the medial and radial nerve dermatomes, and complete reversal of vasospasm was evident five minutes after the injection. All five fingers had been cold and blue before the injection, but colour and temperature became normal when compared with the other hand.

Two weeks later, the patient reported nearly complete pain relief. Her muscle weakness persisted, with residual numbness only in the fifth finger. A second axillary block was performed using an identical low-volume technique. Two weeks after the second selective axillary block, the patient demonstrated full muscle strength in her hand and arm, and she denied pain or numbness. The oral prednisone was discontinued, and a third axillary block was performed.

Over the next six weeks, the patient received three additional blocks, and the steroid myopathy resolved. Her muscle strength gradually returned to her pre-morbid state, and she was again able to walk without wheelchair assistance. At evaluation four months later, the patient demonstrated none of the sequelae of reflex sympathetic dystrophy.

\section{Discussion}

Reflex sympathetic dystrophy is characterized by unrelenting intense burning pain that may follow minor trauma or illness. Generally vasoconstrictive in nature, vasomotor instability is usually present. Atrophy of musculature distal to the injury is common, and the findings do not necessarily follow anatomical distributions expected to result from an injury to a single peripheral nerve. The onset of pain generally precedes the vasomotor changes, and atrophy is often among the last physical findings to appear. Reflex sympathetic dystrophy can immediately follow injury of it may begin slowly and insidiously. The constellation of symptomatology is dynamic and changes in severity. Although it generally increases in intensity, the pain as it first appears may spread to non-dermatomal distributions within a variable time.

For decades, sympathetic block has been a successful treatment of causalgia and reflex sympathetic dystrophy.' Percutaneous blockade to the lumbar sympathetic plexus is appropriate for treatment of lower extremity causalgia and stellate ganglion blockade for treatment of upper extremity causalgia. ${ }^{2-4}$ Additional treatment approaches have been employed, including reserpine and guanethidine Bier blocks, and oral calcium channel blockers. ${ }^{5-7}$

The incidence of iatrogenic reflex sympathetic dystrophy is unknown, but is probably low. ${ }^{8}$ Several surgical procedures have been implicated in the development of this complication, but there are no clear predisposing factors.

The diagnosis of causalgia is often missed until relatively late in its progression. Delay in diagnosis results in delay in treatment, which often renders successful treatment more difficult.

Incidental medical or surgical conditions may limit therapeutic options. In this case, the patient's recovery from carotid endarterectomy altered the anatomy and prevented the conventional anterior approach to stellate ganglion block, thus necessitating an alternative axillary approach. Axillary block has been previously described as an effective treatment of reflex sympathetic dystrophy. ${ }^{9}$ Standard approaches to axillary block in adults used anaesthetic volumes of 10 to $50 \mathrm{ml}$, but generally larger volumes are preferred to ensure adequate blockade. ${ }^{10}$ In this case, however, we used one-tenth of the recommended standard volume " to accomplish differential, "selective" blockade of the injured ulnar nerve sparing the blockade to the other nerves travelling in the axillary sheath. Selective blockade was planned in order that steroid could be applied with the greatest concentration to the injured nerve and allowing the least dosage possible: methylprednisolone $40 \mathrm{mg}$ was diluted to a total volume of only $3 \mathrm{ml}$.

In spite of the classic presentation of RSD, it was expected that there would be some element of inflammation, given the nature of the injury. Parenteral steroids have been observed to be beneficial in some patients with RSD, ${ }^{12}$ and this patient responded to oral prednisone. For these reasons the steroid was included in the block mixture. A long-acting steroid preparation was chosen in an attempt to capitalize on the "depo" base which delays the distribution and metabolism of the methylprednisolone. This same lipid base could theoretically prolong the action of the local anaesthetic as well.

Epinephrine was added to prolong the block duration thereby prolonging autonomic block, as well. This is a controversial decision. While RSD is generally vasoconstrictive in presentation, this represents hyperdynamic 
sympathetic efferent outflow. Small doses of epinephrine are unlikely to worsen vasoconstriction through direct pharmacological action. Paradoxically, the addition of epinephrine will prolong local anaesthetic action, and the autonomic block will in turn be prolonged.

This case demonstrated that the blockade of a single peripheral nerve rapidly reversed vasospasm and pain over a widespread area. The success of this approach implies that total sympathetic block of an extremity might not be necessary to treat some presentations of RSD.

\section{References}

1 Schumacker $H B$, Speigel IJ, Upjohn RH. Causalgia I. The role of sympathetic interruption in treatment. Surg Gynecol Obstet 1948; 86: 76-86.

2 Wang JK, Johnson $K A$, Ilstrup DM. Sympathetic blocks for reflex sympathetic dystrophy. Pain 1985; 23: 13-7.

3 Evans JA. Reflex sympathetic dystrophy: report on 57 cases. Ann Intern Med 1947; 26: 417-26.

4 Patman RD, Thompson JE, Persson AV. Management of post-traumatic pain syndromes. Ann Surg 1973; 177 : 780-7.

5 Chuinard G, Dabezies EJ, Gould JS, Murphy GA, Matthews $R E$. Intravenous reserpine for treatment of reflex sympathetic dystrophy. South Med J 1981; 74: 1481-4.

6 Hannington-Kiff JG. Intravenous regional sympathetic block with guanethidine. Lancet 1974; 1: 1019-20.

7 Prough DS, McLeskey CH, Poehling GC et al. Efficacy of oral nifedipine in the treatment of reflex sympathetic dystrophy. Anesthesiology 1985; 62: 796-9.

8 Horowitz $\mathrm{SH}$. latrogenic causalgia: classification, clinical findings and legal ramifications. Arch Neurol 1984: 41: $821-4$.

9 Defalque JR. Axillary versus stellate ganglion blocks for RSD of the upper extremity. Regional Anesthesia 1984; 9: 35 .

10 Moore $D C$. Axillary approach for block of the brachial plexus. Regional Block. Springfield, CC Thomas, Inc., 1979.

11 Carron H, Korban GA, Rowlingson JC. Regional Anesthesia: Techniques and Clinical Applications. Orlando. Grunt \& Stratton, Inc., 1984.

12 Christensen $K$, Jensen $E N$, Noer $I$. The reflex dystrophy syndrome response to treatment with systemic corticosteroids. Acta Chir Scand 1982; 148: 653-5. 